\title{
Active power based distance protection scheme in the presence of series compensators
}

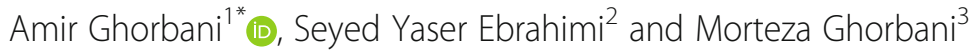

\begin{abstract}
Flexible ac transmission system (FACTS) controllers, especially the series-FACTS controllers, affect the operation of distance relays and can lead to the relays under/over-reaching. This paper aims to demonstrate the effects of static synchronous series compensator (SSSC) and series capacitive compensation (SCC), as two important series compensators, on the distance protection using theoretical and computational methods. The results of the investigation are used to develop a feasible and adequate method for eliminating the negative effects of these devices on the distance relays. The developed method measures the voltages at terminals of the SSSC and SCC by phasor measurement units (PMUs) which are then transmitted to the relay location by communication channels. The transmitted signals are used to modify the voltage measured by the relay. Different operation types and conditions of SSSC and SCC, and different faults such as phase-to-phase and phase-to-ground faults are investigated in simulations. Since the modeled distance relay can measure the fault resistance, trip boundaries are used to show the performance of the presented method. Results show that the presented method properly eliminates the negative effects on the distance relays and prevents them from mal-operation under all fault resistance conditions.
\end{abstract}

\section{Introduction}

The operation of FACTS controllers and their response to the variations in the power system, either made by operators or faults, is sufficiently fast to affect the voltage and current signals measured by the protection relays. These variations in the signals produce a substantial delay in the relay's operation and usually lead to their under-reaching. There have been many efforts dedicated to investigating these effects in different power protection systems. Majority of the studies have tackled these effects on impedance relays like the distance relays of transmission lines and loss-of-excitation (LOE) relays of synchronous generators, both of which are based on impedance measurements. Investigations in [1-11] analyze the distance relay performance in the presence of FACTS controllers. These studies can be categorized into three major parts based on different compensation devices: a) shunt-FACTS like static Var compensator

\footnotetext{
* Correspondence: ghorbani_a@abhariau.ac.ir

${ }^{1}$ Department of Electrical Engineering, Abhar Branch, Islamic Azad University, Abhar, Iran

Full list of author information is available at the end of the article
}

(SVC) and static synchronous compensator (STATCOM) [1-4], b) series-FACTS like SSSC and thyristor controlled series capacitor (TCSC) [5-7], and c) shuntseries-FACTS like generalized interline power flow controller (GIPFC) and unified power flow controller (UPFC) [8-11]. In [7], the impact of SSSC on distance relay performance was studied. In this paper, conventional distance relay was used with no capability of $R_{f}$ calculation. The paper did not present any algorithm to remove the impact of SSSC on the relay performance. The results in these papers show that the series and shunt-series FACTS controllers have severer negative effects on the operation of distance relays than other devices due to the increased zero component of the injected voltage along the fault. Also, it is shown that the most severe effect occurs under phase-to-ground fault condition which usually results in the relays underreaching.

In the aforementioned investigations, the author has justified the existing FACTS controllers effect on the mho impedance relays operation and therefore, it is 
necessary to revise the protection algorithm of these relays to eliminate or at least decrease the negative effects on them. Majority of recent studies use the PMUs to measure the voltage and current which are injected by the FACTS because these controllers are usually located in the middle of the transmission line and it is necessary to transmit the measured data to the relays location. This method is used in [11] to modify the distance relay operation in the presence of UPFC using a generalized regression neural network algorithm. In [12], the signals of the PMUs, which are located at both ends of the transmission line, are transmitted to relay location to eliminate the negative effects of GIPFC on the impedance based loss-of-excitation relay. Also, investigations in [13-15] utilize PMUs to eliminate the effects of the series capacitive compensators on the distance relays. In [16], the synchrophasors are used to mitigate the effects of phase-shifting transformer on the distance relay.

This paper shows that the commonly used series compensators, e.g. SSSC and SCC, can cause the distance relays mal-operation and distort the backup protection. A simple and feasible method which uses the equivalent circuit of the SSSC and SCC to modify the distance relays is then presented to eliminate the detrimental effects of the SSSC and SCC on the measured impedance of the distance relays. Synchrophasors are used to calculate the voltage and current signals in the buses and communication channels are used to transfer them to the system protection center (SPC). Consequently, according to the developed new algorithm, fault resistance and compensator effects are removed and fault location can be precisely detected. In [11-16], the presented methods were used for faults with small fault resistance $\left(R_{f}\right)$ or only improved the performance of Zone-3. In addition, the studied algorithms were complicated and the SSSC was not always considered. In contrast, this study considers all of the mentioned issues and the results show that the presented method eliminates the negative effects of the SSSC and SCC under all of the different operation conditions. Signal transmission delay is also counted in the simulations and it shows that the presented method does not slow down the response of the relay.

\section{Modeling of system with SSSC and distance relays}

The power system under study as shown in Fig. 1a comprises three transmission lines each with $200 \mathrm{~km}$ lengths. The series compensator is located at the middle of line-2 and the distance relays, each with three protection Zones, are located at the beginning of the lines. For example, Zone- 1 of the relay $R_{A}$, comprises $80 \%$ of the transmission line-1; Zone- 2 comprises the whole of line1 and $50 \%$ of line-2; and Zone- 3 comprises the whole of lines- 1 and 2 and also $20 \%$ of line-3. The other relays have been set similarly to $R_{A}$. Also, applying delays to the operation of Zones- 2 and 3 of the distance relays creates the backup protection. The modelled distance relays can measure the fault resistance. Since highresistance faults cause the relays under-reaching, different methods have been presented to eliminate the under-reaching [16-21]. The feasible and simple method of [16] and [21] is used in this study in which the currents and active powers are measured at the buses of the transmission line with PMUs. These signals are then transmitted to the relay location to calculate $I_{f}=I_{C}+I_{B}$ and $R_{f}$ is calculated as:

$$
R_{f}=\frac{P_{B}+P_{C}-x R_{L 2}\left(I_{B}\right)^{2}-(1-x) R_{L 2}\left(I_{C}\right)^{2}}{\left(I_{B}+I_{C}\right)^{2}}
$$

Since the line resistance is negligible in comparison with the fault resistance, it is omitted from (1) and thus it can be simplified as:

$$
R_{f} \cong \frac{P_{B}+P_{C}}{\left(I_{f}\right)^{2}}
$$

Once $R_{f}$ is known, its effects can be easily eliminated on the A-G element. The detailed model of the SSSC which comprises a 48-pulse voltage source convertor is present in MATLAB [22] and is used in the modeling here. The SCC model also has a fixed capacitor and a parallel controlled switch in each of the phases. The characteristics of the power system are presented in [23]. Power system parameters have been provided in appendix.

\section{Impact of SSSC and SCC on distance protection}

The positive, zero and negative sequence networks of the power system from the viewpoint of the $R_{B}$ relay are shown in Fig. 1b. In this figure, the series compensators are considered as a variable voltage source because the SSSC acts like a controllable series voltage source. Also, SCC has a series impedance making the SCC like a variable or controllable voltage source while the current following through this impedance. The positive sequence voltage at the $R_{B}$ relay location $\left(V_{1 B}\right)$ can be expressed as:

$$
V_{1 B}=x Z_{1 L} I_{1 B}+R_{f} I_{1 f}+\Delta V_{1}+V_{1 f}
$$

The negative $\left(V_{2 B}\right)$ and zero $\left(V_{O B}\right)$ sequence voltages are obtained from Fig. 1 in the same way as:

$$
V_{2 B}=x Z_{1 L} I_{2 B}+R_{f} I_{2 f}+\Delta V_{2}+V_{2 f}
$$

and

$$
V_{0 B}=x Z_{0 L} I_{0 B}+R_{f} I_{0 f}+\Delta V_{0}+V_{0 f}
$$

For a single phase-to-ground fault, the following equations can be obtained:

$$
I_{B}=I_{1 B}+I_{2 B}+I_{0 B}
$$




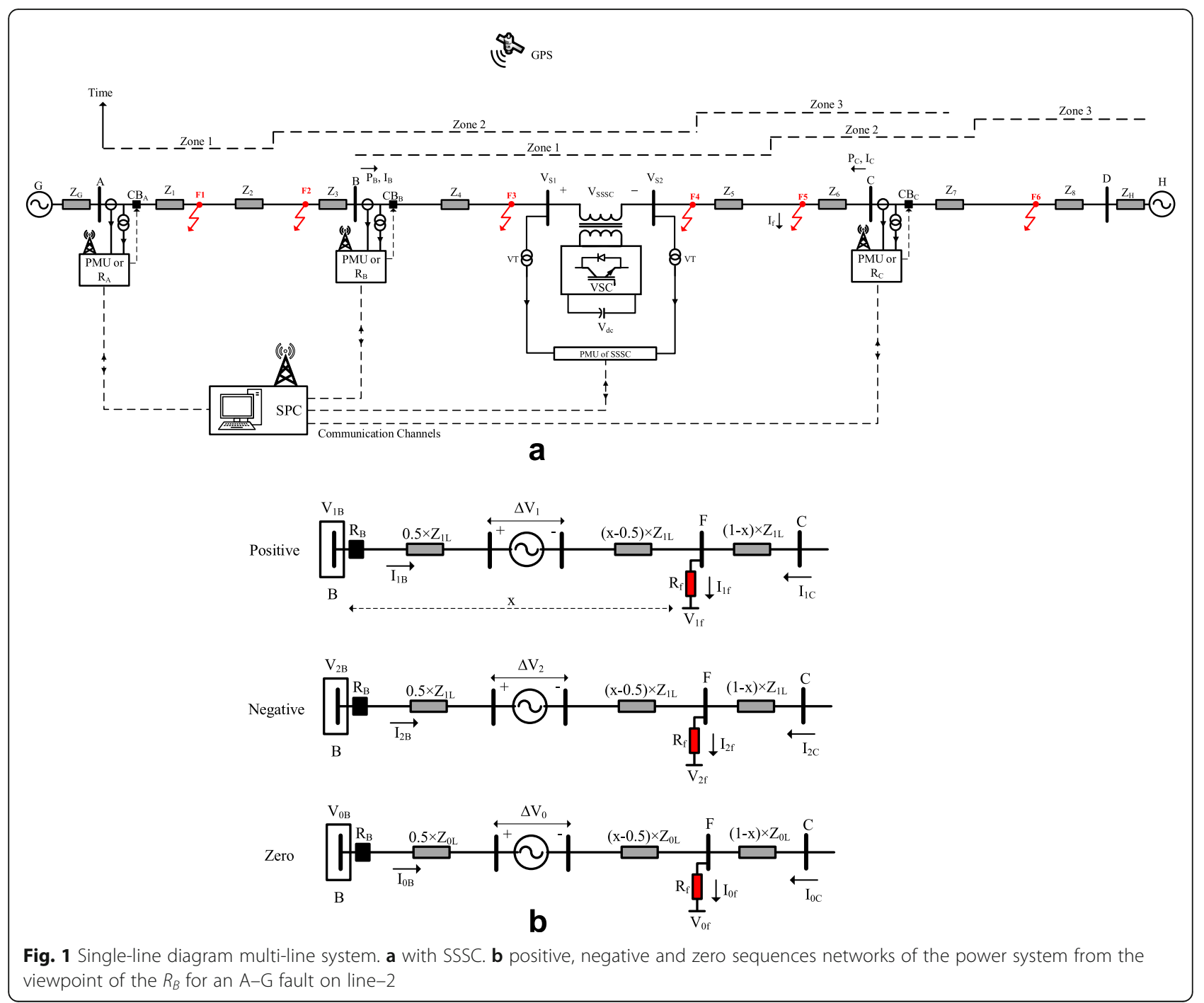

$$
\begin{aligned}
& I_{f}=I_{1 f}+I_{2 f}+I_{0 f} \\
& \Delta V=\Delta V_{1}+\Delta V_{2}+\Delta V_{0}
\end{aligned}
$$

and

$$
V_{B}=V_{1 B}+V_{2 B}+V_{0 B}
$$

Substituting the calculated $V_{1 B}, V_{2 B}$ and $V_{O B}$ into (9) and considering the fact that $V_{1 f}+V_{2 f}+V_{O f}=0$ is valid for single phase-to-ground fault, following equation can be derived:

$$
\begin{aligned}
& V_{B}=V_{1 B}+V_{2 B}+V_{0 B} \\
& =x Z_{1 L} \underbrace{\left(I_{1 B}+I_{2 B}+I_{0 B}\right)}_{I_{B}}-x Z_{1 L} I_{0 B} \\
& +R_{f} \underbrace{\left(I_{1 f}+I_{2 f}+I_{0 f}\right)}_{I_{f}}+x Z_{0 L} I_{0 B} \\
& +\underbrace{\left(\Delta V_{1}+\Delta V_{2}+\Delta V_{0}\right)}_{\Delta V} \\
& =x Z_{1 L} I_{B}+x I_{0 B}\left(Z_{0 L}-Z_{1 L}\right)+R_{f} I_{f}+\Delta V
\end{aligned}
$$

For a single phase-to-ground fault (A-G) on line-2, the apparent impedance seen by $R_{B}$ relay is as follows [24]:

$$
\begin{aligned}
Z_{A-G} & =\frac{V_{B}}{I_{B}+I_{0 B}\left(\left(Z_{0 L}-Z_{1 L}\right) / Z_{1 L}\right)}=\frac{V_{B}}{I_{A-G}} \\
& =x Z_{1 L}+\underbrace{R_{f} \frac{I_{f}}{I_{A-G}}}_{\Delta Z_{R f}}+\underbrace{\frac{\Delta V}{I_{A-G}}}_{\Delta Z_{A-G}}
\end{aligned}
$$

For a single phase-to-ground fault, the impact of series compensator on the apparent impedance is expressed by $\Delta Z_{A-G}$ and the series voltage of the compensator has a direct impact on the apparent impedance. For a phaseto-phase fault, one can write:

$$
Z_{A-B}=\frac{V_{1 B}-a \cdot V_{2 B}}{I_{1 B}-a \cdot I_{2 B}}
$$


where $a=-0.5+$ j0.866. Substituting $V_{1 B}$ and $V_{2 B}$ from (3) and (4) into (12) yields:

$$
\begin{gathered}
Z_{A-B}=\frac{V_{1 B}-a V_{2 B}}{I_{1 B}-a I_{2 B}} \\
=\frac{\left(x Z_{1 L} I_{1 B}+R_{f} I_{1 f}+\Delta V_{1}+V_{1 f}\right)-a\left(x Z_{1 L} I_{2 B}+R_{f} I_{2 f}+\Delta V_{2}+V_{2 f}\right)}{I_{1 B}-a I_{2 B}}
\end{gathered}
$$

and

$$
Z_{A-B}=\frac{x Z_{1 L}\left(I_{1 B}-a I_{2 B}\right)+R_{f}\left(I_{1 f}-a I_{2 f}\right)+\left(\Delta V_{1}-a \Delta V_{2}\right)+\left(V_{1 f}-a V_{2 f}\right)}{I_{1 B}-a I_{2 B}}
$$

Simplifying (14) and taking into account of $V_{1 f}+a V_{2 f}=$ 0 in case of $A-B$ fault yield:

$$
Z_{A-B}=x Z_{1 L}+\underbrace{R_{f} \frac{\left(I_{1 f}-a I_{2 f}\right)}{I_{1 B}-a I_{2 B}}}_{\Delta Z_{R f}}+\underbrace{\frac{\left(\Delta V_{1}-a \Delta V_{2}\right)}{I_{1 B}-a I_{2 B}}}_{\Delta Z_{A-B}}
$$

$R_{f}$ is the fault resistance between the two phases in (15). For a phase-to-phase fault, the impact of compensator on the apparent impedance is expressed by $\Delta Z_{A-B}$. Since the series compensator affects the calculated impedance via the voltage across the terminals $(\Delta V)$, if this voltage is known and is transmitted to the relay location, the problems emanating from these voltage changes can be solved. In section IV, this method is investigated by simulations. Simulation results for single phase-toground fault, A-G, $150 \mathrm{~km}$ away from $R_{B}$ relay (F1 fault) are shown in Fig. 2. This fault occurs at Zone-2 of $R_{A}$ relay and Zone- 1 of $R_{B}$ relay. Presented results in Fig. 2 show that the relays detect the fault in their correct zones when the SSSC is not connected to line-2. The presence of SSSC increases the impedance calculated by the relays and makes both relays to under-reach. These under-reaching are very severe, and consequently, the fault falls into none of the protection zones of the relays. The results presented in Fig. 2 include both capacitive $\left(V_{R e f}=0.1\right)$ and inductive $\left(V_{R e f}=-0.1\right)$ operation modes of the SSSC. As it can be seen in this figure, the SSSC causes relays under-reaching during both capacitive and inductive operation modes, though it is more severe in inductive mode than in capacitive mode. The cause for under-reaching is due to the zero component of injected voltage as has been precisely explained in [7]. Exclusive discussions about the SSSC effects on distance relays operation are also presented in [7]. Herein, the main objective of the paper is to investigate the method for eliminating these negative effects.

\section{Modified distance protection}

Nowadays, synchrophasors are commonly used to improve the operation of power systems such as relays and stabilizers. This method uses PMUs to measure the required information at different locations of the power system and send them to the controlling center. These data can then be used to generate proper control signals to improve the operation of the system. Communication channels such as optical fibers are used in this method to transmit the data. Since the data are sent from

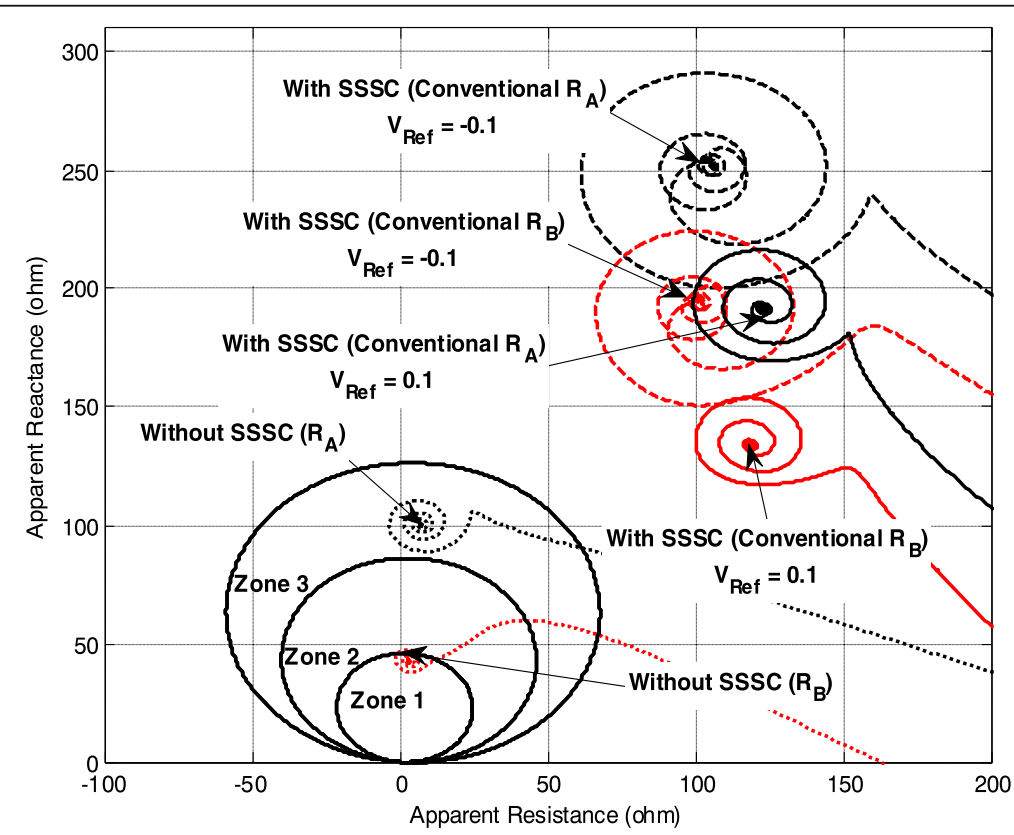

Fig. 2 Apparent impedance seen by conventional relays for an $A-G$ fault at $150 \mathrm{~km}$ from the $R_{B}$ 


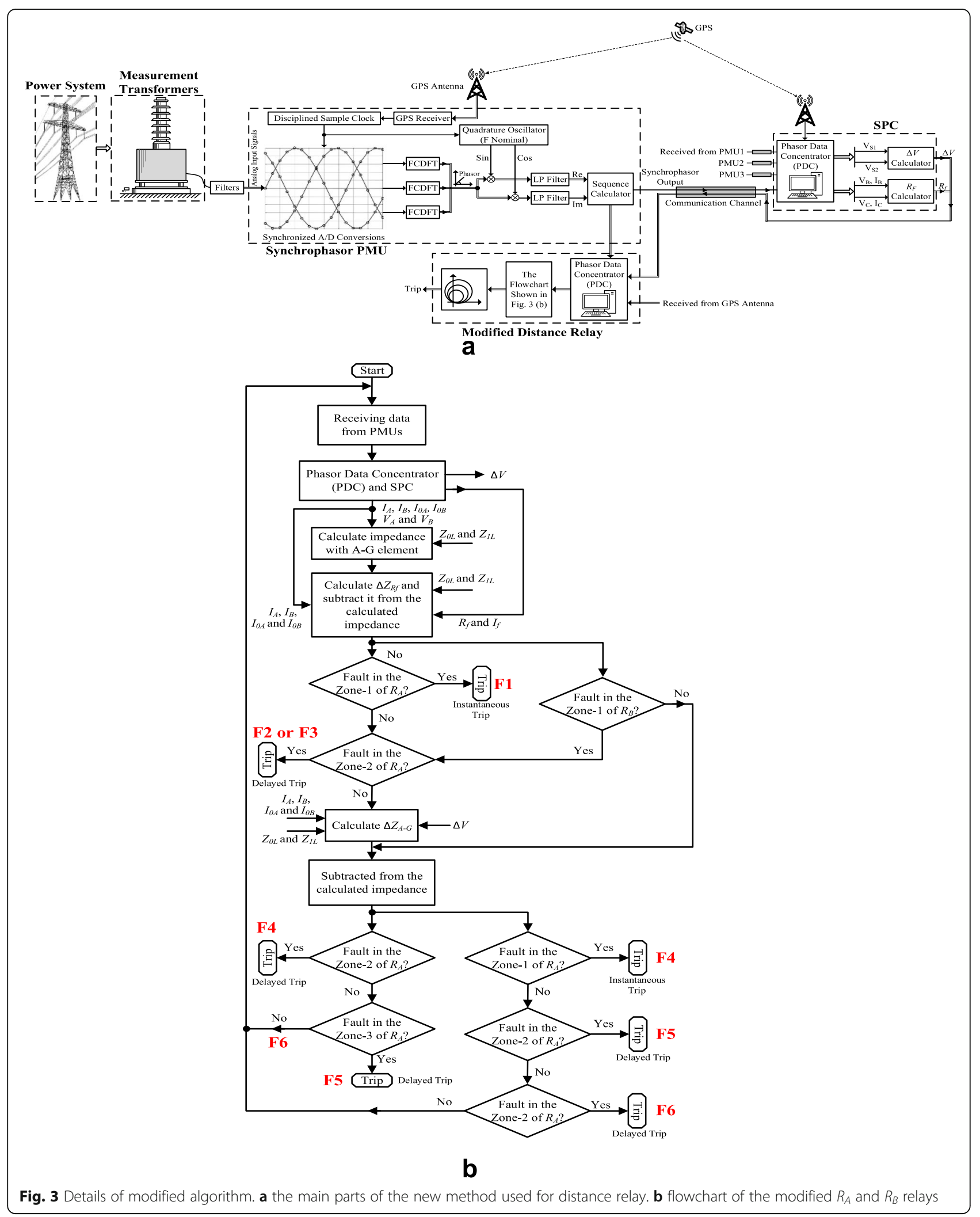


different locations with different delays, it is necessary to synchronize and make them time stamped using the global positioning system (GPS) $[25,26]$. In the presented method, a relay or PMU is considered at the beginning of the transmission line. Existence PMU at the beginning of the transmission line-2 (bus B to C) plays the role of the PMU at the end of the transmission line-1 (bus A to B) [27]. Therefore, for the power system presented in Fig. 1a, the values of $V_{A}, V_{B}, V_{C}, I_{A}, I_{B}$ and $I_{C}$ signals are available in SPC. As seen in the theoretical analyses results, the presence of series compensators changes the impedance calculated by the relays caused by the equivalent voltage of the series compensators. To eliminate this issue, the voltages of both compensator terminals are measured as shown in Fig. 1a and are sent to SPC using communication channel. The method used in this paper is more precisely presented in Fig. 3a. It should also be mentioned that it is necessary to synchronize the relay signals with the signals sent by the PMUs from the compensator locations. The analog signals are filtered first and are then converted into digital signals by synchronized A/D conversions [28]. The phasors are calculated by the PMUs using the full cycle discrete fourier transform (FCDFT) method. The phasors are used to determine the sequences of the signals. Finally, voltage across the series compensator $(\Delta V)$ and the fault resistance $\left(R_{f}\right)$ are calculated and sent to the distance relays. The calculated signals are synchronized again using phasor data concentrator (PDC) and are used to determine the fault by the six elements of the relay. At the relay location, the $\Delta V$ voltage is deducted from the relay measured voltage to eliminate the series compensator effect. Different locations are chosen for the faults as shown in Fig. 1a. The flowchart shown the modified algorithms of the $R_{A}$ and $R_{B}$ relays is given in Fig. 3b. Figure 1a and the flowchart show different scenarios about the fault (F1-F6) for different locations. The flowchart presents A-G element and will be the same for other faults, only the impedance calculation will change. Zone- 2 of the $R_{A}$ relay covers the middle of line-2 (bus $B$ to $C$ ) but the SSSC is also located in the middle of line-2. Therefore, if the fault occurs in the right side of the SSSC in Fig. 1a, the SSSC will be located in the fault loop. However, if the fault occurs in the left side of the SSSC in Fig. 1a, the SSSC will not be located in the fault loop and the fault will be detected in the end of Zone- 2 of $R_{A}$ relay. These issues are presented in the flowchart with F3 and F4. Herein, the simulation results for different operation modes of the compensator and different types of faults are presented.

\section{With SSSC}

Simulation results for A-G fault in $150 \mathrm{~km}$ away from $R_{B}$ relay are shown in Fig. 4. According to this figure, the modified method has eliminated the errors of the relays and made them capable of detecting the fault in the proper zone. The results for phase-to-phase fault (A-B) are presented in Fig. 5a and b for $V_{R e f}=0.3$ and -0.3 , respectively. Comparing these results with the phase-toground fault (Fig. 2) reveals that the phase-to-ground faults have severer effects on the operation of the relays. Furthermore, the phase-to-phase faults make the relay become over-reach. Similar to the phase-to-ground fault, the modified algorithm can eliminate the errors in the relay operation under phase-to-phase faults too.

The results for different fault types at different locations and under different SSSC operation modes are

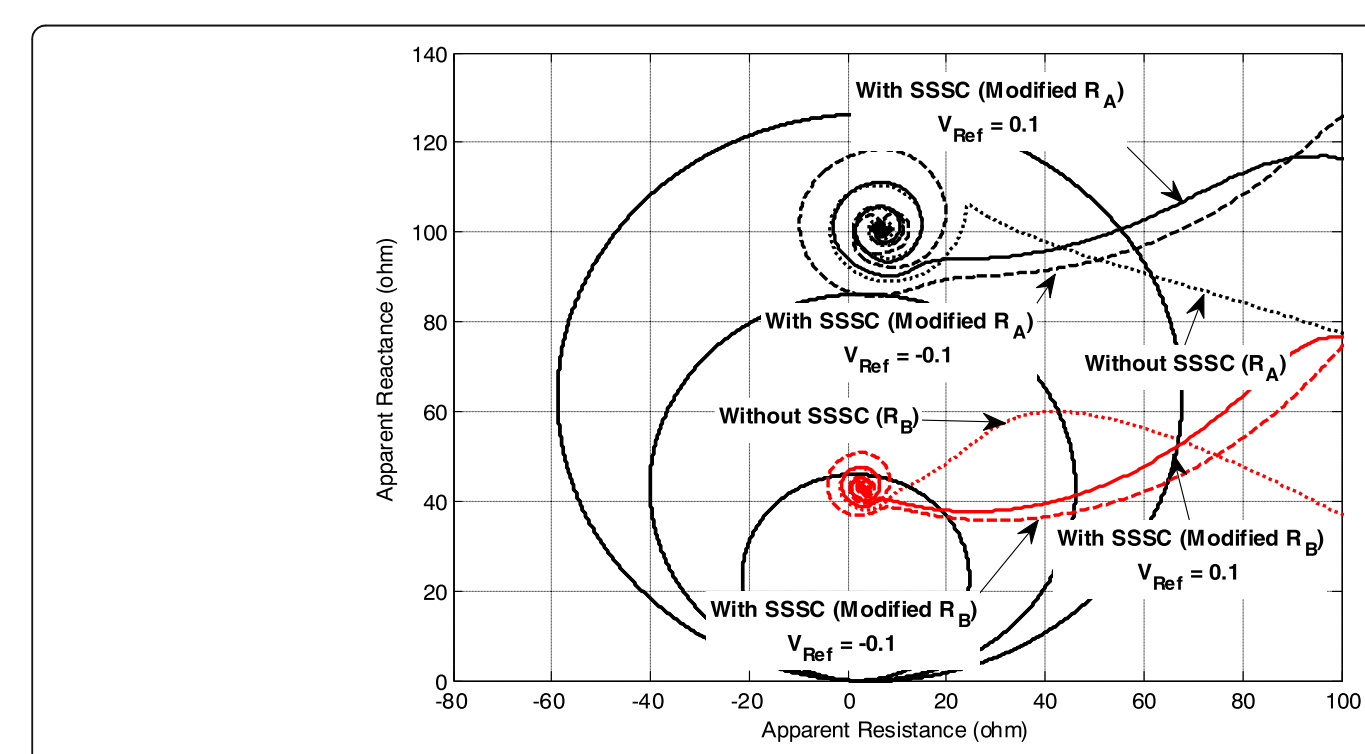

Fig. 4 Calculated apparent impedance by modified relays for an A-G fault at $150 \mathrm{~km}$ from the $R_{B}$ 


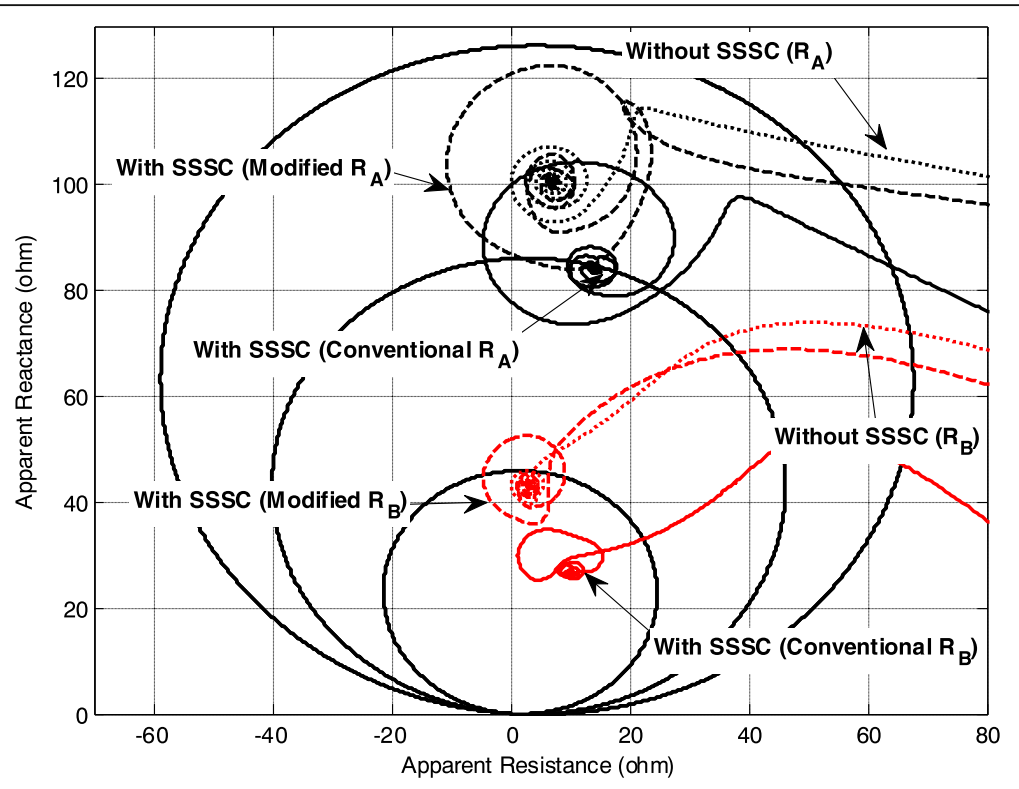

a

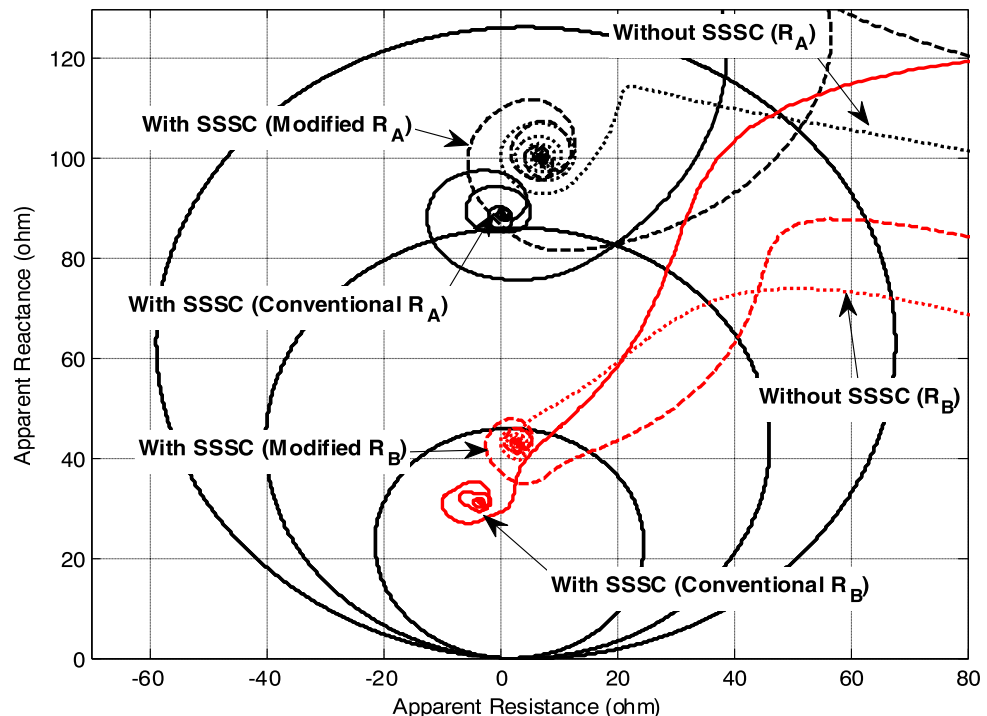

b

Fig. 5 Calculated apparent impedance by relays for an $A-B$ fault at $150 \mathrm{~km}$ from the $R_{B}$ a results for $R_{A}$. a $V_{\text {Ref }}=0.3$. b $V_{\text {Ref }}=-0.3$

presented in Table 1 . The fault locations are intentionally chosen such that the SSSC falls into the desired fault loops. The distances in Table 1 show where the faults are located with respect to the $R_{A}$ relay. The following equation is used to calculate the data presented in Table 1:

$$
\text { Error }=\left|Z_{W O}-Z_{W}\right|
$$

where $Z_{W O}$ and $Z_{W}$ are the relay measured impedance without and with the SSSC connected to the line respectively. Regarding Table 1 for all the $V_{\text {Ref }}$ values, the SSSC effect under phase-to-ground faults is more severe than phase-to-phase faults. For instance, the maximum impedance differences due to SSSC effect for A-G and A-B faults are 183 and $24.7 \Omega$ respectively. For A-G faults, the SSSC effect decreases as $V_{\text {Ref }}$ increases while for A-B faults the SSSC effect increases with increasing $V_{\text {Ref. }}$ Also, the SSSC effect decreases as the distance between the A-G fault and the relay increases while its effect increases as the distance between the $\mathrm{A}-\mathrm{B}$ fault and the relay increases. For 
Table 1 Performance of conventional (CON) and modified (MOD) distance relay with the presence of SSSC and SCC

\begin{tabular}{|c|c|c|c|c|c|c|c|c|c|c|c|}
\hline & & \multirow{2}{*}{$\begin{array}{l}\text { Fault distance from } R_{A} \\
\text { Method }\end{array}$} & \multicolumn{2}{|l|}{$310 \mathrm{~km}$} & \multicolumn{2}{|l|}{$350 \mathrm{~km}$} & \multicolumn{2}{|l|}{$400 \mathrm{~km}$} & \multicolumn{2}{|c|}{$450 \mathrm{~km}$} & \\
\hline & & & CON & MOD & CON & MOD & CON & MOD & CON & MOD & \\
\hline \multirow[t]{8}{*}{ With SSSC } & A-G Fault & $V_{\text {Ref }}=0.1 \mathrm{p} . \mathrm{u}$ & $149 \Omega$ & $0.039 \Omega$ & $147 \Omega$ & $0.033 \Omega$ & $144 \Omega$ & $0.037 \Omega$ & $140 \Omega$ & $0.125 \Omega$ & Calculated by (16) \\
\hline & & $V_{\text {Ref }}=0.3 \mathrm{p} . \mathrm{u}$ & $116 \Omega$ & $0.046 \Omega$ & $115 \Omega$ & $0.022 \Omega$ & $114 \Omega$ & $0.020 \Omega$ & $112 \Omega$ & $0.005 \Omega$ & \\
\hline & & $V_{\text {Ref }}=-0.1$ p.u & $183 \Omega$ & $0.032 \Omega$ & $180 \Omega$ & $0.038 \Omega$ & $176 \Omega$ & $0.043 \Omega$ & $170 \Omega$ & $0.040 \Omega$ & \\
\hline & & $V_{\text {Ref }}=-0.3 \mathrm{p} . \mathrm{u}$ & $112 \Omega$ & $0.023 \Omega$ & $107 \Omega$ & $0.016 \Omega$ & $100 \Omega$ & $0.134 \Omega$ & $91.8 \Omega$ & $0.024 \Omega$ & \\
\hline & A-B Fault & $V_{\text {Ref }}=0.1 \mathrm{p} . \mathrm{u}$ & $3.53 \Omega$ & $0.012 \Omega$ & $4.3 \Omega$ & $0.004 \Omega$ & $5.46 \Omega$ & $0.003 \Omega$ & $6.69 \Omega$ & $0.004 \Omega$ & \\
\hline & & $V_{\text {Ref }}=0.3 p . u$ & $15.2 \Omega$ & $0.026 \Omega$ & $17.8 \Omega$ & $0.038 \Omega$ & $21.2 \Omega$ & $0.018 \Omega$ & $24.7 \Omega$ & $0.039 \Omega$ & \\
\hline & & $V_{\text {Ref }}=-0.1 \mathrm{p} . \mathrm{u}$ & $2.30 \Omega$ & $0.018 \Omega$ & $2.5 \Omega$ & $0.002 \Omega$ & $3.67 \Omega$ & $0.213 \Omega$ & $4.18 \Omega$ & $0.114 \Omega$ & \\
\hline & & $V_{\text {Ref }}=-0.3 p . u$ & $11.7 \Omega$ & $0.018 \Omega$ & $13.3 \Omega$ & $0.034 \Omega$ & $16.1 \Omega$ & $0.007 \Omega$ & $19.1 \Omega$ & $0.101 \Omega$ & \\
\hline \multirow[t]{6}{*}{ With SCC } & A-G Fault & 20\% Compensation & $7.25 \Omega$ & $0.004 \Omega$ & $7.24 \Omega$ & $0.010 \Omega$ & $7.28 \Omega$ & $0.027 \Omega$ & $7.48 \Omega$ & $0.040 \Omega$ & \\
\hline & & $50 \%$ Compensation & $18.3 \Omega$ & $0.009 \Omega$ & $18.3 \Omega$ & $0.013 \Omega$ & $18.5 \Omega$ & $0.026 \Omega$ & $18.9 \Omega$ & $0.038 \Omega$ & \\
\hline & & 70\% Compensation & $25.5 \Omega$ & $0.012 \Omega$ & $25.9 \Omega$ & $0.020 \Omega$ & $26.3 \Omega$ & $0.032 \Omega$ & $26.8 \Omega$ & $0.052 \Omega$ & \\
\hline & A-B Fault & $20 \%$ Compensation & $11.4 \Omega$ & $0.021 \Omega$ & $11.5 \Omega$ & $0.027 \Omega$ & $11.4 \Omega$ & $0.048 \Omega$ & $11.5 \Omega$ & $0.080 \Omega$ & \\
\hline & & 50\% Compensation & $28.7 \Omega$ & $0.043 \Omega$ & $28.6 \Omega$ & $0.017 \Omega$ & $28.6 \Omega$ & $0.066 \Omega$ & $28.7 \Omega$ & $0.033 \Omega$ & \\
\hline & & 70\% Compensation & $40.2 \Omega$ & $0.005 \Omega$ & $40.2 \Omega$ & $0.027 \Omega$ & $40.1 \Omega$ & $0.048 \Omega$ & $40.2 \Omega$ & $0.091 \Omega$ & \\
\hline
\end{tabular}

instance, for A-G fault with $V_{R e f}=0.1$, the impedance difference decreases from 149 to $140 \Omega$ when the distance increases from $310 \mathrm{~km}$ to $450 \mathrm{~km}$. Finally, the comparison between the conventional relay and the modified relay shows that the modified method decreases the impedance difference to less than $0.2 \Omega$ for all different types of faults under all operation conditions. For example, the impedance difference with the conventional method is $183 \Omega$ but is decreased to 0.032 $\Omega$ using the modified method. In other words, the modified method eliminates the SSSC negative effects under any system operation conditions.

\section{With SCC}

The simulation results for $\mathrm{A}-\mathrm{G}$ and $\mathrm{A}-\mathrm{B}$ faults in the presence of SCC are presented in Fig. 6a and b, respectively. The faults are $110 \mathrm{~km}$ away from the relay $R_{B}$ and the presented results refer to $50 \%$ compensation. As shown, the presence of SCC decreases the relay measured impedance and causes the relay over-reach. Furthermore, using the voltages of both SCC terminals eliminates its effect on the relay measured impedance. Simulation results for different compensations and different fault locations are presented in Table 1. As can be seen, the over-reaching severity increases as the compensation percentage increases. Unlike the SSSC, the SCC effect under phase-to-phase faults is more severe than phase-to-ground faults. The modified method eliminates the SCC negative effects on the relay. For example, the maximum measured impedance difference for $70 \%$ compensation during the $\mathrm{A}-\mathrm{B}$ fault occurring $310 \mathrm{~km}$ away from the relay $R_{A}$ is $40.2 \Omega$ and is reduced to $0.005 \Omega$ with the new modified method.
The results presented above refer to zero fault resistance. Further investigation into the feasibility and ability of the modified method in the presence of the SSSC and SCC under high-resistance faults conditions is carried out in the following sections.

\section{High resistance fault}

Application of trip boundaries is a trustworthy method for evaluating the effect of fault resistance on the measured impedance by the relay. The fault location and resistance are considered as two important parameters in this method. At the first step, the fault is located at the beginning of the transmission line and the fault resistance $\left(R_{f}\right)$ is increased from zero to $300 \Omega$. This evaluation for the relay $R_{B}$ is presented in Fig. 7a, in which the locus follows the path "AB". At the second step, the fault resistance is fixed at $300 \Omega$ and the location is changed from the beginning to the end of the transmission line. This step makes the path "BC" in Fig. 7a. At the third step, the fault is located at the end of the line and the fault resistance is changed from $300 \Omega$ to zero which makes the path "CD" in Fig. 7a. At the final step, the fault resistance is fixed to zero and the location is changed from the end to the beginning of the transmission line which makes the path "CA" in Fig. 7a. The increments of $R_{f}$ and fault location are set at $30 \Omega$ and $20 \mathrm{~km}$, respectively. The results presented in Fig. 7 include both capacitive $\left(V_{R e f}=0.3\right)$ and inductive $\left(V_{R e f}\right.$ $=-0.1$ ) operation modes of the SSSC. According to the results presented in Fig. 7, for majority of the capacitive mode the calculated impedance does not fall into the proper protection Zones. The trip boundaries for A-G fault in the presence of 70\% SCC are presented in Fig. 7c. 


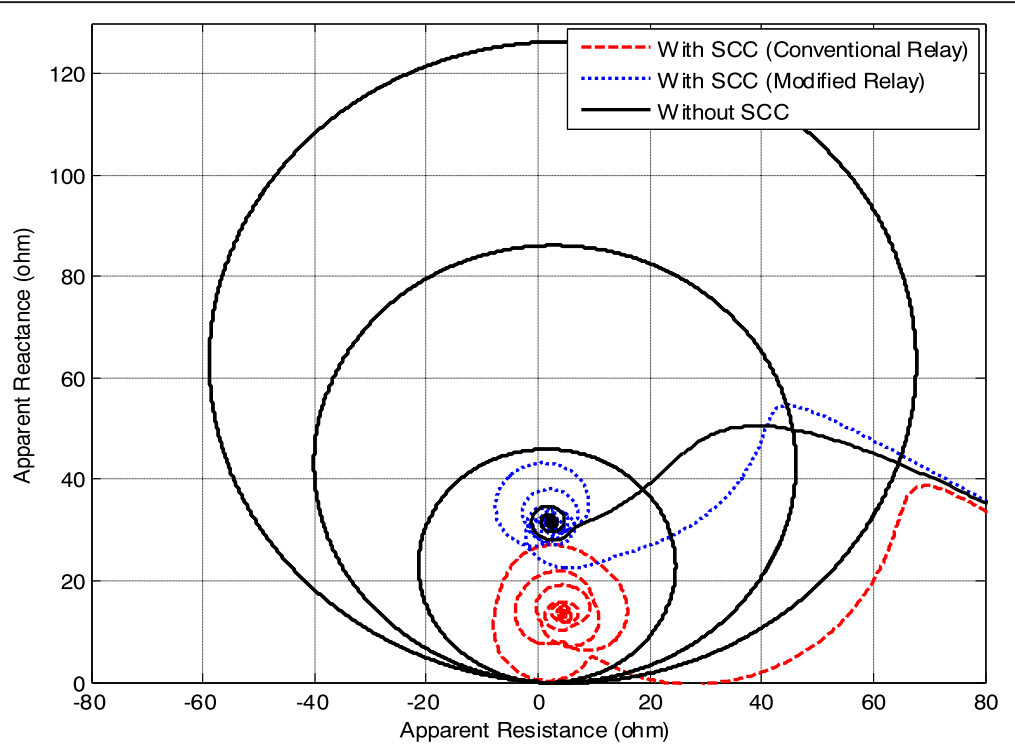

a

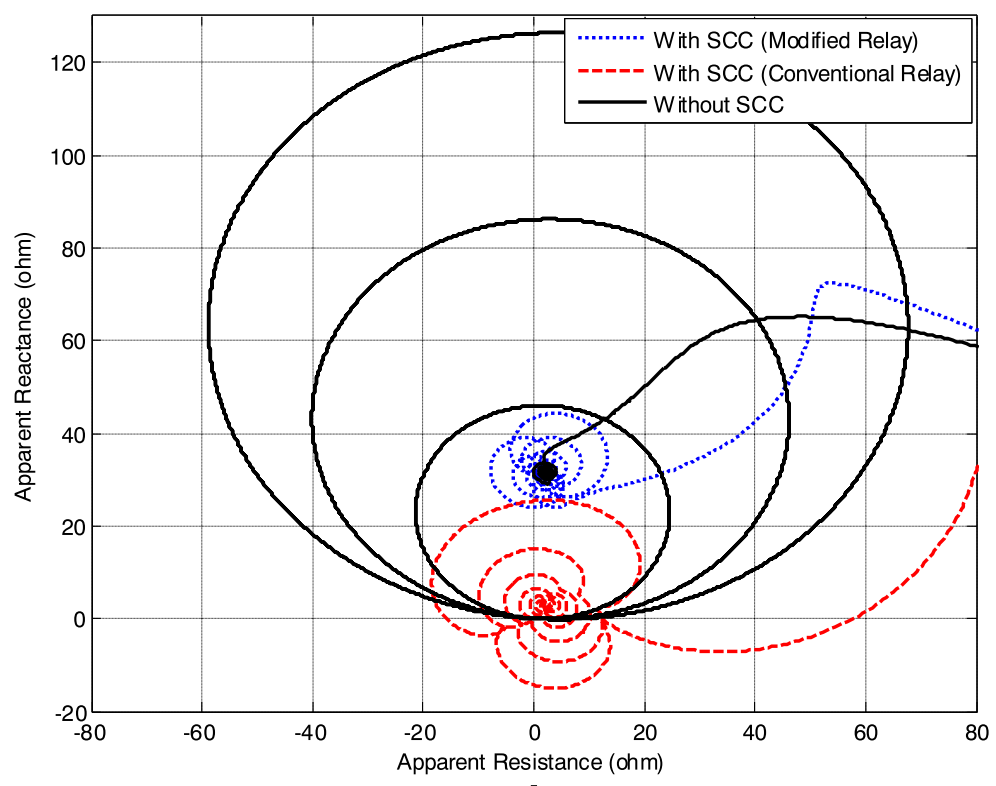

b

Fig. 6 Calculated apparent impedance by $R_{B}$ relay for a fault at $110 \mathrm{~km}$ from the $R_{B}$. a A-G fault b A-B fault

It is worth mentioning that the SSSC changes the trip boundaries more than the SCC does. It is also seen that the presence of series compensator divides the trip boundaries into two parts: part- 1 for the faults occurring at the left hand side of the compensator and part- 2 for the faults occurring at the right hand side of the compensator. For part-2, the compensator locates in the fault loop. However, when the fault occurs at the left hand side of the compensator (i.e. part-1), the compensator does not locate at the fault loop and only affects the measured impedance if its resistance is not zero.

\section{Response time of modified distance relay}

The amount of delay can be divided in two parts: the first part is related to PMU calculation (using the mentioned algorithm) and data transmission by fiber optic, and the second part of the delay is related to the protection zones of the distance relay. For the first part delay:

$$
t=\Delta t_{m}+\Delta t_{\text {up }}+\Delta t_{\text {syn }}+\Delta t_{\text {down }}+\Delta t_{a}
$$

where $\Delta t_{m}$ is the delay caused by PMU including the time for synchrophasor sampling and calculation. $\Delta t_{u p}$ is 


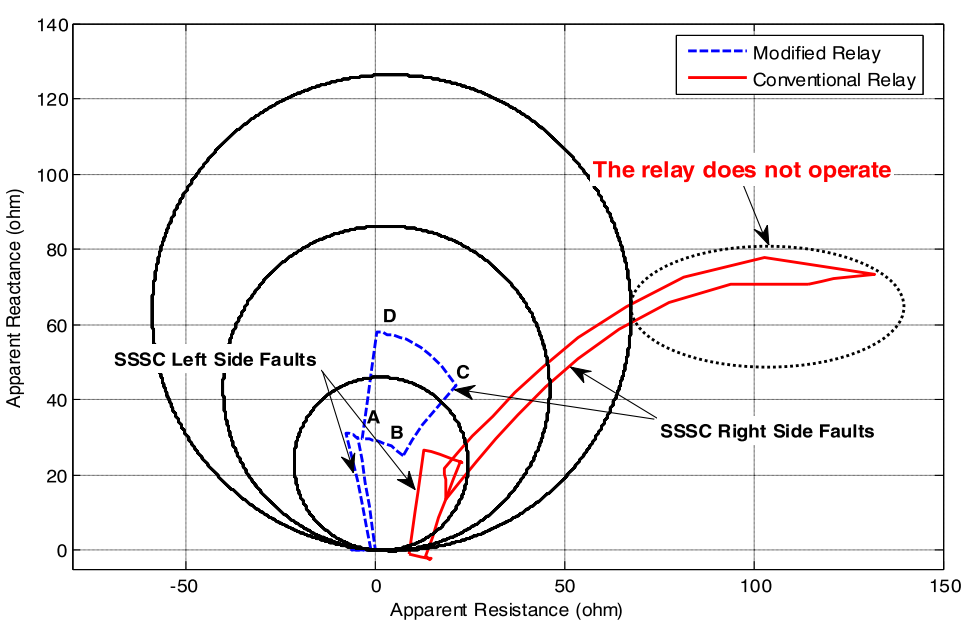

a

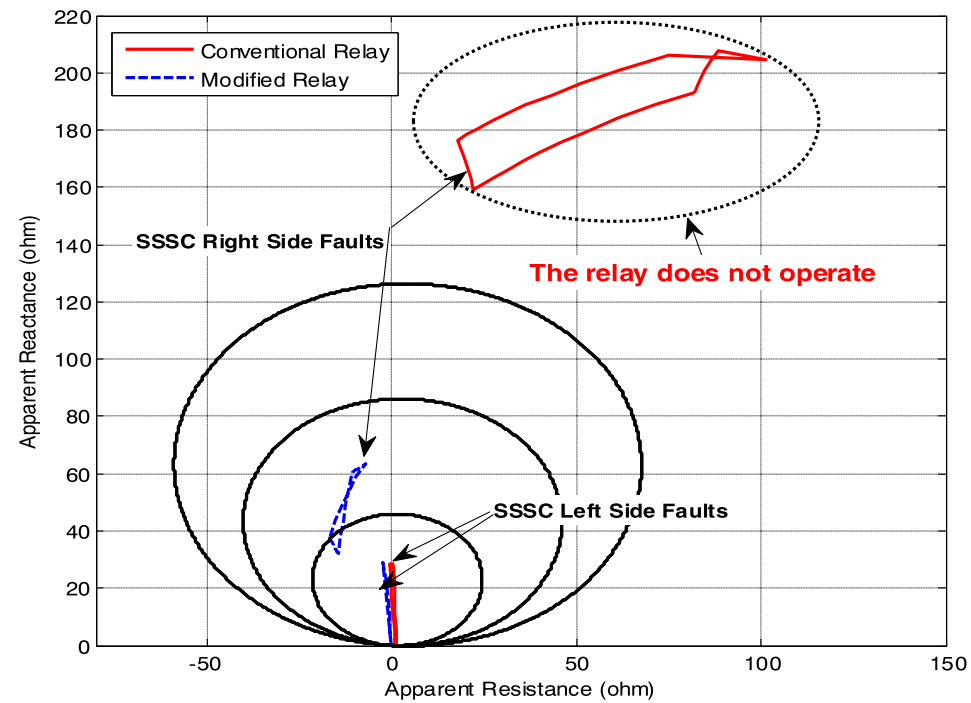

b

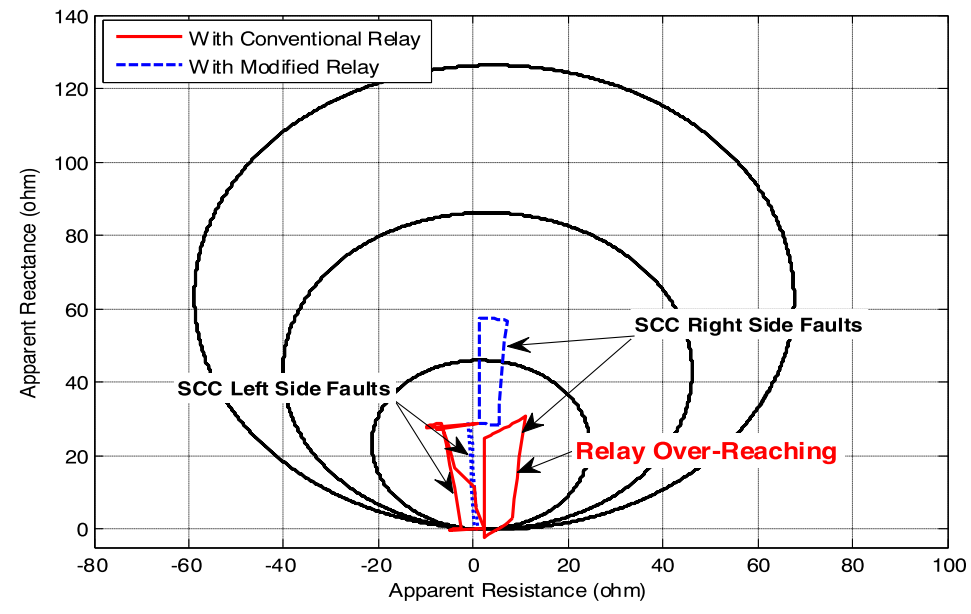

C

Fig. 7 Trip boundaries calculated by the A-G element of $R_{B}$. $\mathbf{a}$ in the presence of SSSC, $V_{R e f}=0.3 . \mathbf{b}$ in the presence of SSSC, $V_{R e f}=-0.1$. $\mathbf{c}$ in the presence of SCC (70\% compensation) 
the delay for transmitting data from PMU to PDC through communication channels. $\Delta t_{s y n}$ is the sum of delay required by PDC to synchronize the PMU data. $\Delta t_{\text {down }}$ is the delay for transmitting the $\Delta V$ signal from the PDC to the relay through forward channels. $\Delta t_{a}$ is the delay required by PDC to synchronize the received data [28]. For the second part of the delay, the distance relay has three operation zones: Zone-1 without delay, Zone-2 has $0.5 \mathrm{~s}$ delay and Zone-3 has $1.0 \mathrm{~s}$ delay. In other words, if the measured impedance placed in each of the zones, the trip signal will be sent after the related delay. Results are presented for different scenarios in Table 2 where factors such as the fault type, the fault location, the $V_{R e f}$ of SSSC are considered for modified (MOD) and conventional (CON) methods. As can be seen in the CON method, there are a lot of cases that the relay does not detect fault (shown by "Not Oper"). The numbers shown in Table 2 indicate the amount of delay in the relay operation. These numbers are written in two parts as $t_{1}+t_{2}$. The first part $\left(t_{1}\right)$ is related to the delay of the operation zones of the relay which is adjustable and is used for backup protection and the second part $\left(t_{2}\right)$ is related to the algorithm delay. The cases that the first part is zero indicate that the relay detects the fault in its first zone (Zone-1) with zero delay. For example, for fault A-B at $295 \mathrm{~km}$ of the $R_{B}$ relay with $V_{R e f}$ $=0.3 \mathrm{p} \cdot \mathrm{u}$ and using the conventional method, the delay is calculated as $t_{1}+t_{2}=1.0+0.114 \mathrm{~s}$. In other words, the $1.0 \mathrm{~s}$ is the delay of Zone- 3 and $0.114 \mathrm{~s}$ is the delay of the conventional method calculation. As it can be seen that the actual fault is in Zone-2 and is located at 295 $\mathrm{km}$ away from $R_{B}$ relay but the presence of compensator causes the fault to be falsely detected as in Zone-3 and the amount of $t_{1}$ is equal to $1.0 \mathrm{~s}$. Using the modified algorithm, the delay is calculated as $t_{1}+t_{2}=0.5+0.422 \mathrm{~s}$. In other words, the new algorithm avoids the relay maloperation, the fault is properly identified in Zone-2 and the amount of $t_{1}$ is equal to $0.5 \mathrm{~s}$. The comparison between the two results shows that $t_{2}$ in the conventional method is $0.114 \mathrm{~s}$ but in the modified method it is increased to $0.422 \mathrm{~s}$ as fiber optic is used. This issue can be compensated by decreasing the protection zones delay which compensates the increased algorithm delay time. As an example, it is possible to decrease the delay of Zone-3 from $1.0 \mathrm{~s}$ to $0.5 \mathrm{~s}$.

This issue is further explained in Fig. 8. It is assumed that at $\mathrm{t}=0 \mathrm{~s}$ a fault occurs in Zone-2 and for the conventional method without compensator it is shown by "A". The compensator causes the relay under-reach, the fault is detected as in Zone- 3 and causes the delay of zone or $t_{1}$ become bigger. This issue is shown by "B" and causes the relay performance time to become longer than the desired value. It has to be considered that the method is similar in " $\mathrm{A}$ " and " $\mathrm{B}$ " and $t_{2}$ becomes equal in these states. However, by applying the modified method (shown by "C"), the relay correctly detects the fault in Zone-2 and $t_{1}$ is equal to that in " $\mathrm{A}$ ". In this method, the calculating time is slightly increased so $t_{2}$ become longer and the relay performance time also become slightly longer than the desired value. In " $\mathrm{D}$ ", the delay time of zone and $t_{2}$ are reduced leading to improved relay performance time.

\section{Conclusion}

The effects of two types of series compensators, SSSC and SCC, on the impedance measured by distance relays have been investigated in this paper. The theoretical and simulation results showed that the presence of these compensators substantially affect the relay operation. The effects of SSSC are more severe than those of SCC, and the SSSC effects under phase-to-ground faults are also more severe than those under phase-to-phase faults. Capacitive and inductive compensations of SSSC make the relay under-reaching and over-reaching, respectively. On the contrary, the SCC always make the relay overreach which is more severe for phase-to-phase faults than phase-to-ground faults. Studies under different SSSC $V_{\text {Ref }}$ conditions and different series compensation percentages showed that the distance relay operation changes due to the presence of SSSC and SCC, which

Table 2 Operation time of CON and MOD relay with the presence of SSSC and considering the set-delay times of zones

\begin{tabular}{|c|c|c|c|c|c|c|c|c|}
\hline & \multirow{2}{*}{$\begin{array}{l}\text { Fault distance from } R_{B} \\
\text { Method }\end{array}$} & \multicolumn{2}{|l|}{$155 \mathrm{~km}$} & \multicolumn{2}{|l|}{$295 \mathrm{~km}$} & \multicolumn{2}{|l|}{$400 \mathrm{~km}$} & \\
\hline & & $\mathrm{CON}$ & MOD & $\mathrm{CON}$ & MOD & $\mathrm{CON}$ & MOD & \\
\hline \multirow[t]{4}{*}{ A-G Fault } & $V_{\text {Ref }}=0.1 \mathrm{p} . \mathrm{u}$ & Not Oper & $0+0.415$ & Not Oper & $0.5+0.433$ & Not Oper & $1.0+0.437$ & Operation time (Sec) of relay \\
\hline & $V_{\text {Ref }}=0.3 \mathrm{p} . \mathrm{u}$ & Not Oper & $0+0.414$ & Not Oper & $0.5+0.422$ & Not Oper & $1.0+0.420$ & \\
\hline & $V_{\text {Ref }}=-0.1 \mathrm{p} . \mathrm{u}$ & Not Oper & $0+0.415$ & Not Oper & $0.5+0.416$ & Not Oper & $1.0+0.443$ & \\
\hline & $V_{\text {Ref }}=-0.3$ p.u & $1+0.128$ & $0+0.416$ & Not Oper & $0.5+0.416$ & Not Oper & $1.0+0.504$ & \\
\hline \multirow[t]{4}{*}{ A-B Fault } & $V_{\text {Ref }}=0.1 \mathrm{p} . \mathrm{u}$ & $0.5+0.114$ & $0+0.412$ & $1.0+0.115$ & $0.5+0.414$ & $1.0+0.112$ & $1.0+0.403$ & \\
\hline & $V_{\text {Ref }}=0.3 \mathrm{p} . \mathrm{u}$ & $0.5+0.120$ & $0+0.426$ & $1.0+0.114$ & $0.5+0.422$ & Not Oper & $1.0+0.418$ & \\
\hline & $V_{\text {Ref }}=-0.1 \mathrm{p} . \mathrm{u}$ & $0.5+0.116$ & $0+0.418$ & $1.0+0.116$ & $0.5+0.404$ & $1.0+0.112$ & $1.0+0.513$ & \\
\hline & $V_{\text {Ref }}=-0.3$ p.u & $0.5+0.121$ & $0+0.418$ & $1.0+0.114$ & $0.5+0.406$ & Not Oper & $1.0+0.407$ & \\
\hline
\end{tabular}




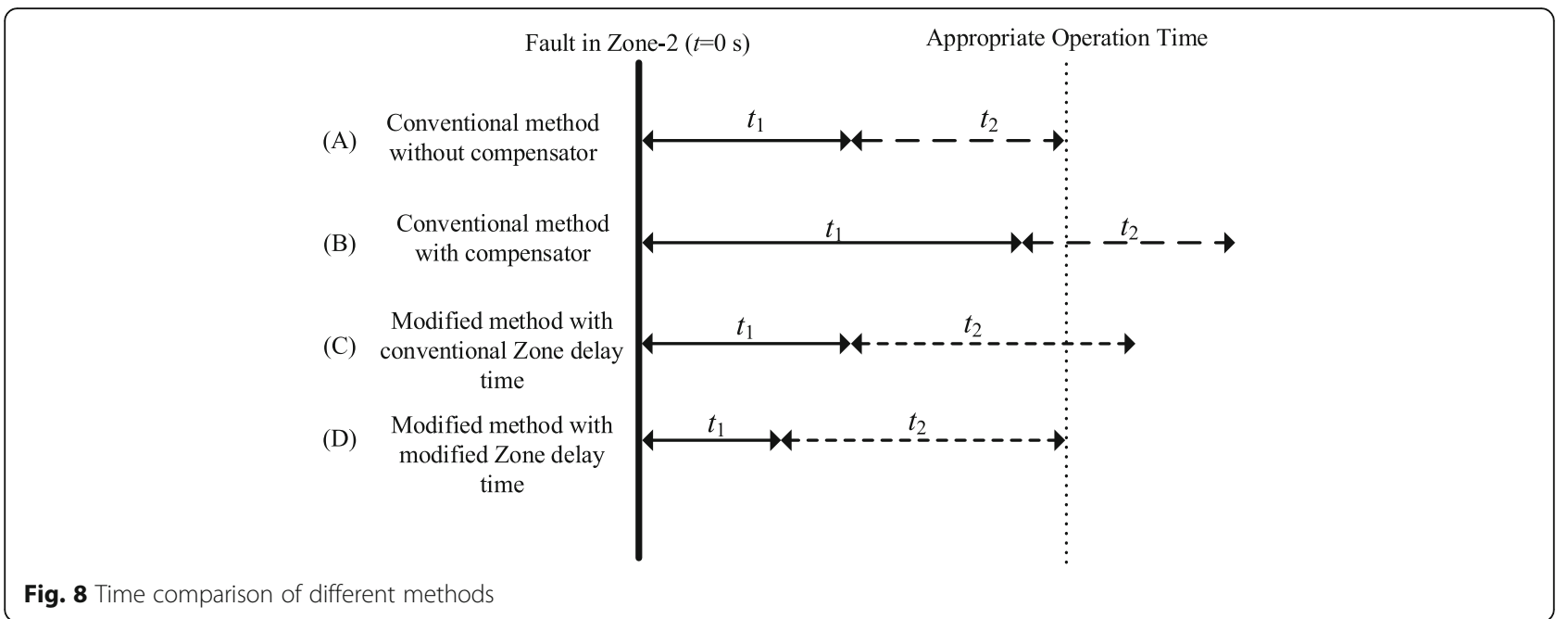

can affect the backup protection of the relay. To eliminate these issues, a PMU-based method was used, in which the voltages of both terminals of the series compensators are measured and transmitted to the relays by communication channels to eliminate the effects of the compensators. Fault resistance using trip boundaries was also studied and it was shown that the series compensators changed trip boundaries and divided them into two parts. Finally, it has shown that by revising the distance relay algorithms the new modified method can easily detect all the faults even for high resistance faults. It has also shown that undesired delay of the new method can be eliminated by changing the set time of the zones of the relay.

\section{Appendix}

The power system parameters are given below:

Voltage Sources: $\mathrm{V}_{\mathrm{G}}=400 \mathrm{kv}, 20 \mathrm{deg}$ and $60 \mathrm{~Hz}, \mathrm{Z}_{1 \mathrm{G}}$ $=1.7431+\mathrm{j} 19.4150 \quad(\mathrm{ohm}), \quad \mathrm{Z}_{\mathrm{OG}}=2.6147+\mathrm{j} 4.9009$ (ohm), $\mathrm{V}_{\mathrm{H}}=0.95 * 400 \mathrm{kv}, 0$ deg and $60 \mathrm{~Hz}, \mathrm{Z}_{1 \mathrm{H}}=$ $0.8716+$ j9.7264 (ohm), $Z_{0 \mathrm{H}}=1.3074+\mathrm{j} 2.4504(\mathrm{ohm})$.

Transmission Lines: Line $-1=$ Line $-2=$ Line $-3=200$ $\mathrm{km}$ and $\mathrm{Z}_{\mathrm{L} 1}=\mathrm{Z}_{\mathrm{L} 2}=\mathrm{Z}_{\mathrm{L} 3}, \mathrm{R}_{1}=0.0201 \mathrm{ohm} / \mathrm{km}, \mathrm{R}_{0}=$ $0.1065 \mathrm{ohm} / \mathrm{km}, \quad \mathrm{L}_{1}=7.6076 \mathrm{e}-4 \mathrm{H} / \mathrm{km}, \mathrm{L}_{0}=.0023$ $\mathrm{H} / \mathrm{km}$.

\section{Authors' contributions}

New authors have greatly cooperated in preparing the new version of manuscript and answering the reviewer's questions. It wouldn't be fair, if we don't add them to the author list. The article includes three main parts which each one has been accomplished by one of the authors. part1: concept and method, par2: Modeling, part3: Analysis. All authors read and approved the final manuscript.

\section{Competing interests}

None of the authors of this paper has a financial or personal relationship with other people or organizations that could inappropriately influence or bias the content of the paper.

\section{Author details}

${ }^{1}$ Department of Electrical Engineering, Abhar Branch, Islamic Azad University, Abhar, Iran. ${ }^{2}$ Young Researchers and Elite Club, Hidaj Branch, Islamic Azad University, Hidaj, Iran. ${ }^{3}$ Department of Electrical, Biomedical and Mechatronics Engineering, Qazvin Branch, Islamic Azad University, Qazvin, Iran.

Received: 13 July 2016 Accepted: 16 January 2017

Published online: 01 March 2017

\section{References}

1. Albasri, F. A., Sidhu, T. S., \& Varma, R. K. (2007). Performance comparison of distance protection schemes for shunt-FACTS compensated transmission lines. IEEE Transactions on Power Delivery, 22(4), 2116-2125.

2. Khederzadeh, M., \& Ghorbani, A. (2011). STATCOM modeling impacts on performance evaluation of distance protection of transmission lines. European Transaction on Electrical Power., 21(8), 2063-2079.

3. Sidhu, T. S., Varma, R. K., Gangadharan, P. K., Albasri, F. A., \& Ortiz, G. R. (2005). Performance of distance relays on shunt-FACTS compensated transmission lines. IEEE Transactions on Power Delivery, 20(3), 1837-1845.

4. Ghorbani, A., Mozafari, B., \& Khederzadeh, M. (2012). Impact of SVC on the protection of transmission lines. International Journal of Electrical Power and Energy Systems., 42(1), 702-709.

5. Samantaray, S. R. (2013). A data-mining model for protection of FACTSbased transmission line. IEEE Transactions on Power Delivery, 28(2), 612-618.

6. Khederzadeh, M., \& Sidhu, T. S. (2006). Impact of TCSC on the protection of transmission lines. IEEE Transactions on Power Delivery, 21(1), 80-87.

7. Ghorbani, A., Mozafari, B., \& Ranjbar, A. M. (2012). Digital distance protection of transmission lines in the presence of SSSC. International Journal of Electrical Power and Energy Systems., 43(1), 712-719.

8. Dubey, R., Samantaray, S. R., \& Panigrahi, B. K. (2014). Simultaneous impact of unified power flow controller and off-shore wind penetration on distance relay characteristics. IET Generation, Transmission \& Distribution, 8(11), 1869-1880.

9. Jena, M. K., Samantaray, S. R., \& Tripathy, L. (2014). Decision tree-induced fuzzy rule-based differential relaying for transmission line including unified power flow controller and wind-farms. IET Generation, Transmission \& Distribution, 8(12), 2144-2152.

10. Khederzadeh, M., \& Ghorbani, A. (2013). Impact of VSC-based multiline FACTS controllers on distance protection of transmission lines. IEEE Transactions on Power Delivery, 27(1), 32-39.

11. Seethalekshmi, K., Singh, S. N., \& Srivastava, S. C. (2011). Synchrophasor assisted adaptive reach setting of distance relays in presence of UPFC. IEEE Systems Journal, 5(3), 396-405.

12. Ghorbani, A., Soleymani, S., \& Mozafari, B. (2015). A PMU-based LOE protection of synchronous generator in the presence of GIPFC. IEEE Transactions on Power Delivery. doi:10.1109/TPWRD.2015.2440314

13. Sarangi, S., \& Pradhan, A. K. (2014). Synchronised data-based adaptive backup protection for series compensated line. IET Generation, Transmission \& Distribution, 8(12), 1979-1986. 
14. Hashemi, S. M., Tarafdar Hagh, M., \& Seyedi, H. (2014). A novel backup distance protection scheme for series-compensated transmission lines. IEEE Transactions on Power Delivery, 29(2), 699-707.

15. Venkatesh, C., \& Swarup, K. S. (2014). Steady-state error estimation in distance relay for single phase to ground fault in series-compensated parallel transmission lines. IET Generation, Transmission \& Distribution, 8(7), 1318-1337.

16. Ghorbani, A., \& Arablu, M. (2015). Ground distance relay compensation in the presence of delta-hexagonal phase shifting transformer. IET Generation, Transmission \& Distribution, 9(15), 2091-2098.

17. Filomena, A. D., Salim, R. H., Resener, M., \& Bretas, A. S. (2008). Ground distance relaying with fault-resistance compensation for unbalanced systems. IEEE Transactions on Power Delivery, 23(3), 1319-1326.

18. Makawana, V. H., \& Bhalja, B. R. (2012). A new digital distance relaying scheme for compensation of high-resistance faults on transmission line. IEEE Transactions on Power Delivery, 27(4), 2133-2140.

19. Xu, Z. Y., Jiang, S. J., Yang, Q. X., \& Bi, T. S. (2010). Ground distance relaying algorithm for high resistance fault. IET Generation, Transmission \& Distribution, 4(1), 27-35.

20. Liu, Q. K., Huang, S. F., Liu, H. Z., \& Liu, W. S. (2008). Adaptive impedance relay with composite polarizing voltage against fault resistance. IEEE Transactions on Power Delivery, 23(2), 586-592.

21. Eissa, M. M. (2006). Ground distance relay compensation based on fault resistance calculation. IEEE Transactions on Power Delivery, 21(4), 1830-1835.

22. SimPowerSystems Toolbox Ver. 5.1, for Use with Simulink, User's Guide 2009. Natick, MA: The MathWorks, Inc.

23. Ghorbani, A. (2015). An adaptive distance protection scheme in the presence of phase shifting transformer. Electric Power Systems Research, 129, 170-177.

24. Liaoand, Y., \& Elangovan, S. (1998). Digital distance relaying algorithm for first zone protection for parallel transmission lines. Proceedings of the Institution of Electrical Engineers C, Generation, Transmission and Distribution, 145(5), 531-536.

25. Chang, L., Chen, G., Gao, W., Zhang, F., \& Li, G. (2014). Adaptive time delay compensator (ATDC) design for wide-area power system stabilizer. IEEE Transactions on Smart Grid, 5(5), 2957-2966.

26. Ree, J. D. L. Centeno, V., Thorp, J. S. \& Phadke, A. G. (2010). Synchronized phasor measurement applications in power systems. IEEE Transactions on Smart Grid, 1(1), 20-27.

27. C37.118: 'IEEE standard for synchrophasor measurements for power systems', 2005.

28. Eissa, M. M., Elshahat, M. M., \& Elanwar, M. M. (2010). A novel back up wide area protection technique for power transmission grids using phasor measurement unit. IEEE Transactions on Power Delivery, 25(1), 270-278.

\section{Submit your manuscript to a SpringerOpen ${ }^{\mathcal{O}}$ journal and benefit from:}

- Convenient online submission

- Rigorous peer review

- Immediate publication on acceptance

- Open access: articles freely available online

- High visibility within the field

- Retaining the copyright to your article 